\title{
Nonpharmacological and pharmacological interventions to prevent or reduce airway
} remodelling

\author{
E.H. Walters*, D.W. Reid*, D.P. Johns* and C. Ward"
}

ABSTRACT: In the present review of airway remodelling and its response to therapies, clinical observations about airway physiological abnormalities, assumed to be caused by remodelling processes, are related to what is known about the components of structural changes from airway sampling and histopathological analysis. The review focuses on three important diseases: asthma, chronic obstructive pulmonary disease and bronchiolitis obliterans syndrome (BOS), which occurs commonly after lung transplantation as a manifestation of chronic rejection. The present authors chose to use BOS as an issue, because with routine bronchoscopic surveillance after lung transplantation there has been more opportunity to directly study airway pathology longitudinally than in more everyday conditions. In addition, the present authors have reviewed animal models of induced airway remodelling, where most information is available on the potential of therapeutic intervention. Finally, the limited information that can be gained from the literature on the effects of commonly used airway medications on remodelling components is reviewed. In conclusion, the present authors have detailed some of the gaps in knowledge surrounding the potential to improve or modulate remodelling processes in human disease. The areas where it is believed urgent research needs to be focused have also been highlighted.

KEYWORDS: Airways, asthma, bronchiolitis obliterans syndrome, chronic obstructive pulmonary disease, pharmacology, remodelling

tructural changes in the airway wall occurring as part of the pathobiology of airways diseases have been referred to as airway remodelling. This has been most extensively studied in asthma, but it also occurs in smokingrelated chronic obstructive pulmonary disease (COPD) [1, 2], cystic fibrosis [3] and obliterative bronchiolitis (OB) following lung transplantation [3]. Research efforts on airway remodelling have been especially driven by the hypothesis that airway structural changes may underlie the development of fixed airflow limitation [4, 5], but appropriate pathophysiological correlations have been limited [6]. There is urgent need for more prospective longitudinal studies of the effects of medication on such relationships [7-9].
COPD is largely a smoking-related disease in which, by definition, there is progressive development of "fixed" (i.e. bronchodilator unresponsive) airflow obstruction. However, many individuals with asthma also develop fixed airflow obstruction, a subject recently reviewed in detail by BAI and KNIGHT [10]. In general, subjects with asthma have narrower airways, even after treatment, than normal individuals, and older asthma patients have more airflow obstruction than younger ones [10]. In the general population, independent risk factors for both postbronchodilator airflow obstruction and also accelerated loss of lung function include a history of asthma and airway hyperreactivity (AHR) [11]. In children, the Childhood Asthma Management

\section{AFFILIATIONS}

*Cardio-Respiratory Research Group Menzies Research Institute, University of Tasmania, Hobart, Australia.

\#Applied Immunobiology and Transplantation Research Group, The Freeman Hospital and University of Newcastle upon Tyne, Newcastle upon Tyne, UK.

CORRESPONDENCE

E.H. Walters

Research Office

Level 3 Clinical School

University of Tasmania

43 Collins Street

Hobart 7001

Australia

Fax: 6162264784

Received:

January 182006

Accepted after revision:

July 302006

STATEMENT OF INTEREST

None declared.

Previous articles in this series: No. 1: Fixman ED, Stewart A, Martin JG. Basic mechanisms of development of airway structural changes in asthma. Eur Respir J 2007; 29: 379-389. No. 2: Bergeron C, Tulic MK, Hamid Q. Tools used to measure airway remodelling in research. Eur Respir J 2007; 29: 596-604. No. 3: Lloyd CM, Robinson DS. Allergen-induced airway remodelling. Eur Respir J 2007; 29: 1020-1032. No. 4: James AL, Wenzel S. Clinical relevance of airway remodelling in airway diseases. Eur Respir J 2007; 30: 134-155. 
Program (CAMP) study $[12,13]$ indicated that duration of asthma, and especially the early onset of disease, contributed to subsequent enhanced airflow obstruction. In addition to having lower spirometric lung function than normal individuals, adult asthma patients have ongoing excess decline in maximal airflow [10, 14]. The Copenhagen City Heart Study [15] found that $23 \%$ of asthmatics developed significant fixed airflow obstruction over a $10-y r$ period, with decline again being greater when the onset of disease was early in life.

Such data have been interpreted as implying that advanced and potentially progressive underlying airway remodelling occurs in the individuals with asthma who develop fixed airflow obstruction. In this view, early onset of asthma may equate to vulnerable airways in the young, being those subjects most susceptible to excessive remodelling; but, perhaps more simply, the case may be that there is more time for progressive remodelling to have a physiological impact.

\section{PROSPECTIVE OBSERVATIONAL CLINICAL STUDIES Asthma}

In 1994, HaAhtela et al. [16] showed that delaying inhaled corticosteroid (ICS) therapy for 2 yrs in newly diagnosed adult asthma led to more fixed airflow obstruction than when treatment was initiated early and continued long term. The more recent Steroid Treatment as Regular Therapy (START) study [17] of 7,000 individuals with mild but persistent asthma, including both children and adults, confirmed the beneficial effects of ICS on this accelerated decline of airway function over a 3-yr period: the rate of decline in post-bronchodilator forced expiratory volume in one second (FEV1) was reduced by $22 \%$ in children and $42 \%$ in adults.

\section{COPD}

Smoking cessation in subjects with COPD leads to a slower rate of lung function decline than in those who continue to smoke, and this is detectable after only 12 months [18]. A number of large studies in COPD have also been performed in recent years to assess whether prolonged treatment with ICS will have a beneficial effect on the accelerated loss of airway calibre in this progressive condition. The results are somewhat mixed. Two recently published meta-analyses $[19,20]$ have also come to somewhat divergent opinions: one suggested a significant positive benefit of $7 \mathrm{~mL} \cdot \mathrm{yr}^{-1}$ less decline in FEV1 in patients treated with ICS, while the other showed a nonsignificant benefit of $5 \mathrm{~mL} \cdot \mathrm{yr}^{-1}$. However, there have been criticisms of the latter review for mistakes in data handling that would underestimate the effect size. In fact, there is currently an as yet unpublished gold-standard Cochrane Review in preparation that has recalculated the advantage of ICS in COPD at $10 \mathrm{~mL} \cdot \mathrm{yr}^{-1}$ (I. Yang and K. Fong, Prince Charles Hospital, Brisbane and University of Queensland, Australia; personal communication).

These studies have suggested, therefore, that the part of the remodelling process which is presumed to lead to airway damage and the development of fixed airflow obstruction is amenable to intervention and reversal, either partially or totally, with conventional inhaled anti-inflammatory therapy. Better definitions of what the most relevant pathophysiological changes in the airways are in inflammatory and remodelling airways diseases, and how these can be affected by medication (or smoking cessation), are open to direct investigation by sampling patients' airway wall tissue per-bronchoscopically; such available studies are reviewed later. However, whether completely reversing all such chronic remodelling changes in airway disease is necessarily beneficial, particularly in asthma, has recently been questioned [10]. The authors suggested, partly from theoretical modelling and partly from occasional items of empirical evidence, that those changes which lead to increased airway stiffness [21] may actually protect the airways from excessive bronchoconstriction.

\section{COMPONENTS AND LOCATION OF AIRWAY REMODELLING}

\section{Asthma}

Remodelling occurs throughout the airway wall and the whole length of the bronchial tree. This was first documented in the classic post mortem studies of HUBER and KOESSLER [22], dating from the early 20th century, and followed up only some decades later [23]. Recently, this has been elegantly confirmed in detailed studies of negative-pressure latex casts of human lung from the University of Calgary (Calgary, AB, Canada). These showed extensive remodelling in fatal and nonfatal asthma, including airway closure due to mucus plugs, elastic bundle and smooth muscle hypertrophy and enlarged mucus gland ducts [24].

The introduction of the flexible fibreoptic bronchoscope in the 1960s resulted in the establishment of safe, in vivo tissue sampling in humans, including the taking of airway biopsies, bronchoalveolar lavage (BAL) and epithelial brushings. This has allowed cross-sectional studies and has also created the potential for longitudinal studies with multiple sampling times. The structural changes in asthmatic airways from such studies were recently and extensively reviewed $[1,4,25]$. They include changes to the airway epithelium and smooth muscle, abnormal deposition of matrix components, angiogenesis, proliferation of airway nerves and hypertrophy of glands. As airway biopsies can readily yield information on the airway epithelium, reticular basement membrane ( $\mathrm{Rbm}$ ) and the immediately underlying lamina propria, there has inevitably been a focus on these structures, with relatively little information on "deeper" areas, i.e. smooth muscle, and the submucosa below the muscularis layer.

\section{COPD}

Relevant aspects of COPD have been reviewed previously [1, 26]. The latest summary from HogG et al. [2] integrates progression of COPD according to the Global Initiative for Chronic Obstructive Lung Disease (GOLD) criteria with remodelling in the small airways $(<2 \mathrm{~mm})$ of 159 lung resection specimens. Progression of COPD was associated with airway wall thickening, the measurement of which included the area bound by the epithelial luminal surface and the connective tissue at the outer limit of the adventitia. Disease progression was also associated with the accumulation of inflammatory mucus exudates and airway inflammation. The aforementioned study used a multiparametric regression analysis to determine the most important associations with disease activity, and showed that the most important determinant of disease progression was remodelling of the airway wall 
made up of changes in the epithelium, lamina propria, smooth muscle and surrounding adventitia [2].

\section{Lung allografts}

Chronic rejection is a major problem for all lung transplant programmes and it manifests pathologically by fibrotic airway remodelling and $\mathrm{OB}$, and functionally by fixed airflow limitation in bronchiolitis obliterans syndrome (BOS). The bronchial epithelium is both a target and a source of damage in its pathophysiology $[27,28]$. In patients with BOS, the current authors have demonstrated frank scarring of the lamina propria, with increased deposition of collagen III [29], and an increase in airway vascular area, which correlated with airflow limitation [30]. BELPERIO et al. [31] have recently shown an increase in airway vessel number in BOS and an abnormal CXC chemokine receptor-dependent angiogenic activity of BAL supernatants. This was found both in patients with BOS and in subjects prior to the detection of BOS, but not in clinically stable patients. These data suggest that, as well as being important in driving neutrophilic airway inflammation, elevated levels of CXC chemokines, such as interleukin (IL)-8, may contribute to airway remodelling and fixed airflow obstruction; not only in BOS but also potentially in asthma and COPD [20, 32, 33].

The hypothesis that the lesions of airway remodelling may be a final common pathway in a number of airway diseases is also suggested by the finding of basement membrane thickening in clinically stable lung transplant recipients [34], a lesion more commonly described in asthma. It has recently been demonstrated, using phenotypic and functional evidence, that epithelial cells may transform into fibroblasts in stable lung allografts through the process of epithelial mesenchymal transition (EMT) [35]. Here, using a combination of airway biopsies and primary epithelial cell cultures from stable allografts, markers of the EMT proteome, including a fibroblast lineage marker (S100A4) and matrix metalloproteinase (MMP)2 and -9 activity, were shown together with functionally invasive epithelial cells. While axiomatic in the embryology, oncology and fibrosis literature, EMT has only recently been described in the airway and its potential role in airways disease such as asthma is still speculative.

The process of EMT forms a possible link between activation and damage of the epithelium, fibrosis and airflow limitation [36]. This concept parallels the emergent importance of the epithelial mesenchymal trophic unit in asthma [4]. Longitudinal data are lacking in lung allografts and, as in asthma, basic questions, such as whether basement-membrane thickening and EMT may in fact be a fundamental protective response to injury, remain unanswered.

\section{ANIMAL MODELS OF AIRWAY REMODELLING AND TRIALS OF PREVENTION AND THERAPY}

There are obvious ethical and logistic limitations to studies of airway pathology in humans, although perhaps these can be exaggerated. In response, animal models of both acute and chronic pathology resembling asthma and COPD have been developed and have been very useful in determining potential cellular and mediator mechanisms, as well as for investigating therapeutic interventions. There are always questions concerning such studies regarding how well they represent equivalent human diseases, but they do seem in general appropriate and informative.

\section{Asthma}

Most models of asthma have used mice with intraperitoneal ovalbumin (OA) and adjuvant sensitisation, with repeat allergen airway challenges over several weeks and occasionally several months. Results may be confounded to some extent by differences in the genetic strain of mouse and details of the protocol used; as a result, differences in the degree, timing and temporal progression of acute inflammation and subacute or chronic remodelling (with accompanying physiological change) can occur $[37,38]$. Even so, such models have shown that airway wall remodelling changes, such as mucous gland and goblet cell hyperplasia, smooth muscle hypertrophy and increased matrix protein deposition, can be induced and at least some aspects can substantially outlast more acute allergic inflammatory changes, especially subepithelial scarring [39].

Gene-knockout and monoclonal-antibody-inhibition studies have suggested a role for the early expression of IL-4 and -13 (but not IL-5) in the development of remodelling, but late inhibition of these cytokines after development of remodelling was not effective, i.e. remodelling could not be reversed [4042]. In contrast, other studies using knockout mice or blocking monoclonals have suggested a more direct relationship between IL-5 production, airway eosinophils and remodelling changes, such as airway fibrosis and smooth muscle hypertrophy [42-45]. Other mouse-model studies have implicated transforming growth factor (TGF)- $\beta 1$ in fibrosis of the airway wall, which itself is related to IL-13 production [46]. It is difficult to know from such mixed messages what the best target might be for anti-cytokine therapy in animals, not to mention for clinical human asthma.

Persistence of remodelling in parallel with increased AHR has been an inconsistent finding in mouse models, even after acute allergic inflammation has resolved [39], but it does occur with chronic house dust mite (HDM) allergen challenges without prior acute sensitisation, which may mirror human disease more closely [47]. A chronic inhalation model using HDM has also recently been developed in sheep [48], with changes (at least in some animals, but not all) observed after 6 months which have close resemblance to human disease. Since sheep lungs are anatomically more similar to those of humans than are mouse lungs and are large enough for repeat airway sampling using bronchoscopy, such a model has major potential for the investigation of mechanisms of disease, as well as of modifying interventions. An attempt to develop a similar model in infant rhesus monkeys [49] has also been successful in mimicking some aspects of (at least more severe) human asthma.

\section{Prevention}

Cessation of the inhalation antigen challenge in an OAsensitised mouse model after 8 weeks led to rapid resolution of airway-wall eosinophilic inflammation and also epithelial mucous cell hyperplasia, but there was no spontaneous reversibility of subepithelial fibrosis and epithelial cell hypertrophy over a 1-month period after allergen exposure ceased [39]. Similar results were obtained after a 1-3-week allergen challenge period and a 1-month allergen avoidance period [50]. 
It was suggested that the relative resistance to spontaneous resolution of remodelling may be related to the accumulation of TGF- $\beta 1$ associated with matrix proteins [39]. The activated TGF- $\beta$ was assumed to originate in epithelial cells that were activated by antigen challenge. Interestingly, AHR resolved quickly in this model after cessation of low-dose allergen. It was proposed that the lack of relationship between AHR and remodelling was due to the absence of airway smooth muscle (ASM) hypertrophy in these mice. The implication is that the stimulus to remodelling changes, or at least some of them, may be ongoing or at best very slowly resolving even after the airway insult has ceased, as shown in the monkey model [51]. Long-term studies of this sort are warranted to explore this issue further, although the mouse model, as evidenced by the lack of smooth muscle changes, may not fully reflect all aspects of human disease.

\section{Physical intervention: bronchial thermoplasty}

Temperature-controlled radiofrequency ablation (thermoplasty) of ASM administered by a bronchoscope is a new intervention undergoing trial as a potential means of sustained reversal of excessive airway narrowing. The rationale is based on the premise that there is no proven evolutionary advantage for the existence of ASM, that its existence is vestigial and that targeted destruction using per-bronchoscopic radiofrequency energy could benefit symptoms and lessen exacerbations. To date there have been positive initial findings in dogs [52], which showed that thermal treatment could reach airways $\geqslant 3 \mathrm{~mm}$ in diameter with selective ablations of ASM and no longer-term damage to adjacent tissue. Reduced AHR to methacholine was also described, probably due to reduced ASM mass, and this effect was maintained for $\geqslant 3$ yrs after treatment. Very recent data in dogs using high-resolution computed tomography to quantify airway size has confirmed that following bronchial thermoplasty the airways maintained a larger luminal area when challenged with methacholine, compared with untreated airways [53].

\section{Therapeutic interventions}

\section{Corticosteroids}

Given the popularity and efficacy of corticosteroids in the management of human asthma, it is inevitable that their effects on remodelling processes in animal models have also been investigated. Such studies have shown positive effects on a number of indices of remodelling $[46,54]$, but these changes seem dependent upon both the timing of the intervention and the dose used.

Thus, in a rat model of OA inhalation over 28 days after initial sensitisation, a dose of inhaled fluticasone propionate (FP), thought to be equivalent to $\sim 2 \mathrm{mg} \cdot \mathrm{day}^{-1}$ in a $70-\mathrm{kg}$ human (i.e. high dose), was administered either concurrently with the allergen challenges or, alternatively, daily for 2 weeks after cessation of allergen challenge. OA challenge in these rats induced cross-sectional airway-wall thickening, enhanced fibronectin deposition in the airway wall, epithelial cell proliferation, goblet cell hyperplasia and physiologically measurable AHR, which persisted after resolution of cellular inflammation. Concomitant treatment with FP decreased all inducible structural and physiological changes, but FP treatment subsequent to the establishment of remodelling changes was unable to reverse them in the very short timescale of the study [55]. It is difficult to draw conclusions from such a shortterm treatment period.

In a subsequent publication, VANACKER et al. [56], again using the same rat model, showed that FP administered concurrently with allergen inhibited both airway eosinophilia and airway wall fibronectin deposition at a much lower dose than that required to inhibit goblet cell hyperplasia and global remodelling, as measured by overall thickening of the airway wall. Thus, it is shown once again that the timing and dosing of the therapeutic intervention may be critical, depending on which aspects of the inflammatory and remodelling process are targeted.

\section{Combined ICS and long-acting $\beta$-agonist}

In clinical human asthma, combining long-acting $\beta$-agonists (LABAs) with ICS has substantial benefit at all levels of ICS dose and it is superior to doubling the dose of ICS [57]. LABA in combination with ICS is not pro-inflammatory and indeed has anti-inflammatory effects on the innate immune system that do not occur with ICS alone [33]. Paradoxically, VANACKER et al. [58] have suggested in their rat model of allergen-induced airway remodelling that combined salmeterol with FP during the last 2 weeks of allergen challenge enhanced airway wall fibronectin and collagen deposition. This was in contrast to FP administered alone which decreased fibronectin but not collagen, although it had positive effects on goblet cell hyperplasia. These effects did not influence AHR. Salmeterol alone as monotherapy did have an anti-eosinophilic effect, but no effect on remodelling changes.

Given the current widespread use of ICS-LABA combination products in the management of asthma, these rather alarming data on the possibility that such treatment may increase matrix protein deposition (which in turn is related to airway wall thickening) need urgent further investigation. This study leaves open the possibility that combination products, although excellent in the short term at symptom control and inflammation resolution, may actually increase long-term airway damage.

\section{Short-acting $\beta$-agonist}

Reliance on regular and frequent short-acting $\beta$-agonists (SABAs) has been thought to lead to deterioration in asthma status in humans, although a systematic review and metaanalysis of the literature has indicated that this is not likely to actually be the case [59]. However, in a rat model of OA sensitisation followed by 4 weeks of regular OA challenge, continuously delivered subcutaneous salbutamol increased allergen-induced epithelial goblet cells hyperplasia and also further enhanced AHR. In contrast, there was no deleterious effect on airway wall thickening, nor on eosinophilic inflammation. The apparent deleterious effects of SABA were prevented by corticosteroid treatment. [60].

\section{Phosphodiesterase inhibitors}

Roflumilast, a selective phosphodiesterase- 4 inhibitor, was used in a mouse OA chronic challenge model. It was found to significantly inhibit epithelial eosinophilia and subepithelial chronic inflammatory cell infiltration, as well as airway wall collagen deposition and epithelial thickening [61]. Unlike 
corticosteroids, it did not inhibit TGF- $\beta 1$ accumulation in the matrix of the lamina propria, suggesting that its mechanism of action on remodelling changes may be different. In contrast, pentoxifylline, a nonselective phosphodiesterase inhibitor, did not affect collagen deposition or subepithelial cellular inflammation, although it did have equivalent effects on epithelial thickening and eosinophilia.

\section{Anticholinergics}

A recent study [62] used a guinea pig model of allergic asthma to investigate structural, biochemical and physiological changes in ASM with repeated aerosolised OA challenge. Repeated challenges over a period of 12 weeks led to an increase in smooth muscle mass in smaller noncartilaginous airways, due to a marked increase in muscle cell hyperplasia rather than hypertrophy. In central airways there was no apparent structural change, but there was an increase in myosin expression and an increase in muscle contractility. All of these changes in muscle were inhibited by nebulised tiotropium (a long-acting M3 cholinergic antagonist). It was proposed that allergen challenge may increase vagal reflex nerve activity or neural acetylcholine release through inhibition of pre-junctional M2 receptors, or that acetylcholine could be directly released from inflammatory and epithelial cells. There may also be reduced acetylcholinesterase activity in asthma. There is some evidence for all of these putative mechanisms from a variety of inflammatory conditions, which were also reviewed [62]. Whatever the cause, increased M3 muscarinic receptor stimulation on smooth muscle cells seems sufficiently able to increase smooth muscle proliferation, as well as potentially sensitising ASM to growth factor stimulation.

There have been no animal studies on the potential for anticholinergics to reverse other classic features of airway remodelling. Tiotropium has not been used much in asthma, in contrast to COPD, but these data suggest that perhaps its possible long-term beneficial effects on AHR and aspects of remodelling, especially on ASM hyperplasia in asthma, ought to be investigated.

\section{Leukotriene modifiers and chromones}

Compared to data on ICS, there have been relatively few studies published concerning these potentially anti-inflammatory agents in the current context [63]. In a mouse model of intraperitoneal $\mathrm{OA}$ sensitisation with periodic nasal $\mathrm{OA}$ challenges, pre-treatment of challenges with the cysteinyl leukotriene antagonist montelukast had a significant inhibitory effect on eosinophil infiltration into the airways. There was a smaller effect on total cellular infiltration, but montelukast had a remarkable effect on the remodelling changes of smooth muscle hyperplasia and subepithelial collagen deposition, essentially abolishing them completely. In this model, unlike in human asthma, there was also extensive intraparenchyma lung fibrosis and this too was completely prevented by montelukast prophylaxis [64].

A leukotriene $(\mathrm{LT}) \mathrm{D}_{4}$ antagonist has also been investigated in a rat model of allergic asthma with $\mathrm{OA}$ sensitisation and repeated aerosol challenge [65]. The $\mathrm{LTD}_{4}$ antagonist MK571, when administered intraperitoneally before each challenge, completely prevented the increase in AHR but had a more modest inhibitory effect on ASM volume increase in central airways (intermediate between the full effects of OA challenge without treatment and the control with saline challenges). In a similar rat OA challenge model, SALMON et al. [66] found a somewhat paradoxical result, in that ASM thickening was attenuated by a 5-lipoxygenase enzyme inhibitor (SB210661), a specific cysteinyl LT (CysLT1) receptor antagonist (pranlukast) and also a $\mathrm{LTB}_{4}$ receptor antagonist (SB201146), but all failed to modify AHR; however, all inhibited eosinophilia. There was also a paradoxical separation between drug effects in inhibiting ASM DNA synthesis and ASM thickening. Also in rats, the substantial airway effects of recombinant IL-13 on inflammation, AHR, mucous hypersecretion and aspects of remodelling (airway fibrosis, fibroblast proliferation including possible differentiation from vascular smooth cells and endothelial changes) were demonstrated to be largely related to 5-lipoxygenase activation and prevented by enzyme inhibition, as well as $\mathrm{LTB}_{4}$ and CysLT1 antagonism [67].

In a rat allergen model, Du et al. [68] demonstrated a more dramatic effect on ASM remodelling with nedocromil (compared with the previous finding with CysLT1 antagonism), at least when administered before OA challenge, which completely prevented the increase in muscle volume induced by the allergen. If administered $2 \mathrm{~h}$ after OA challenge there was a much smaller effect on ASM, although the late asthma response was prevented.

\section{Immunomodulatory DNA}

Over the past decade, the idea that increasing asthma incidence may be related to the cleanliness and relative lack of infectivity of modern advanced-society living has gained credence: the socalled "hygiene hypothesis" of allergic predisposition. The driving issue seems to be the absence of microbial chemicals in the environment needed to "mature" and deviate the infant immune system away from the default position of a T-helper cell (Th)-2-type immune personality. The focus has been on pathogen-associated molecular patterns (PAMPs) associated with microbial organisms which can stimulate the innate immune system through highly conserved, germline-encoded recognition systems on dendritic cells and macrophages, the "pattern recognition receptors" or Toll-like receptors. Innate immune cells stimulated in this way can serve to eliminate the infecting organisms, but also modify the activity of the adaptive, lymphocyte-based immune system through natural killer cells and T-regulatory cells, and their cytokine products, in profound and long-lasting ways. This may "damp down" immune reactions generally or skew the immune response towards a Th1 response with predominant suppression of the Th2 response. The exact outcome is likely to depend upon the specifics of the PAMP, its dose and timing, the species involved, as well as individual genetic susceptibility.

The potential for therapeutic intervention using these insights has led to the development of manufactured mimics of PAMPs: especially methylated oligodeoxynucleotides containing $\mathrm{CpG}$ dinucleotides and palindromic flanking nucleotide sequences. These are common in bacterial DNA but not in vertebrates, including mammals. Strong immune modulatory effects are produced in vivo by such synthetic DNA constructs, termed "immunostimulatory sequence-oligodeoxynucleotides" (ISS-ODN), acting through Toll-like receptor 9. 
A number of studies in mouse allergic models of asthma have been reviewed, indicating that systemic treatment with ISSODN can prevent or reverse the typical Th2/eosinophilic airway inflammation and development of AHR [69]. This can occur with a potency equivalent to high-dose corticosteroid therapy [70]. Furthermore, these effects are partially additive and work through at least some mechanisms which are independent but complementary; for example, the DNA therapy stimulates production of anti-inflammatory, anti-Th2 and pro-Th1 cytokines, unlike the effect of corticosteroid therapy.

Intraperitoneal $\mathrm{CpG}$ oligonucleotides administered at the time of primary sensitisation to $\mathrm{OA}$ in mice can prevent subsequent development of airway remodelling features, as well as allergic inflammation of the airways, with subsequent repeated inhalational challenge over 6 weeks [71]. In this primary prevention study, BAL TGF- $\beta$ levels were increased by ISSODN therapy. In a secondary therapy study of another murine chronic asthma model with sensitisation followed by repeat intranasal allergen over 3-6 months, systemic ISS-ODN administration every 2 weeks decreased or prevented peribronchial collagen deposition, mucus hypersecretion, peribronchial muscle thickening and myofibroblast accumulation in the airway wall [72]. In contrast to the primary prevention study, TGF- $\beta$ levels in BAL were suppressed.

A similarly structured secondary intervention study with ISSODN has been performed in the rhesus monkey model of allergic airway disease induced by aerosolised HDM allergen, but in this case the DNA construct was administered by repeated nebulisation into the airways [73]. These were given seven times over 18 weeks, $24 \mathrm{~h}$ before HDM allergen challenge, and after 20 weeks of fortnightly post-sensitisation allergen exposures. Compared to sham treatment, the ISSODN markedly attenuated AHR, airway eosinophilia, Rbm thickening and mucous cell hyperplasia. Interstitial mucosal mast cell numbers were reduced, but interestingly not numbers of mast cells associated with mucous glands nor ASM-associated mast cells (which are thought to be a particular marker of asthma [74]).

\section{COPD}

COPD is an airway-remodelling and lung parenchymaldestructive disease. It is characterised by progressive airflow obstruction, especially of the smaller airways, and it is associated with epithelial metaplasia, airway inflammation and mucous hypersecretion, and with accompanying variable emphysema due to destruction of the alveolar compartment. It is induced by chronic exposure to irritant gases and dusts, most frequently cigarette smoke, but also other environmental agents more frequently than usually recognised [75].

Research into the pathogenic mechanisms of COPD is relatively poorly developed in comparison to asthma; this is true for both human and animal studies. It has been hoped that the development of animal experimental models will help dissect these mechanisms at a cellular, mediator and genetic level, and lead to new therapeutic strategies and increased willingness to spend research money in this relatively neglected area [76].
Animal models of COPD have involved a number of small animal species, particularly guinea pigs (which appear especially susceptible to COPD changes induced by cigarette smoke), mice, ferrets and rats (which seem especially resistant). Larger animals, such as dogs, can also be made to develop COPD, and sheep models are currently being developed.

Generally, tobacco smoke has been used to generate COPD features of airway inflammation, mucous gland hyperplasia, airway thickening and emphysema in animal models but environmental pollutants, such as sulphur dioxide, nitrogen dioxide and diesel fumes, have also been used [77]. Emphysema is most easily induced by instilling proteolytic enzymes into the airways. Mice have been useful for developing genetic deletion or overexpression models to explore the susceptibility genes for COPD development.

There are major differences in the results of such studies between different species and within strains, e.g. in mice. Such models have limitations in a situation where there is no spontaneous disease and induced models do not necessarily mimic the entire human COPD range of phenotypes. Furthermore, there has been very little focus to date on the details of airway remodelling changes. Historically, most attention has been on the mechanisms underlying emphysema and, more recently, on the details of airway inflammatory infiltrates and related mediator/cytokine profiles. Studies of remodelling have lagged behind and need more urgent research attention.

Animal models of COPD are inevitably being used to trial potential therapies. The effects of a number of innovative compounds, such as potent inhibitors of MMPs, retinoids selective for their $\gamma$-receptor, p38 kinase inhibitors, elastase inhibitors, and also more conventional drugs, such as FP, have been described; but again mainly on airway inflammation, mucous hypersecretion and the development of emphysema [78]. Once more, little attention seems to have been paid to therapeutic modulation of airway remodelling in COPD thus far (table 1).

\section{BRONCHOSCOPIC ASSESSMENT OF INTERVENTIONS IN HUMAN DISEASE}

\section{Nonpharmacological treatment}

Asthma

Allergen and occupational avoidance

There are no direct data on the effects of allergen avoidance on airway remodelling in adults or infants. However, HoLT et al. [79] hypothesised that protection of the growing lung against the effects of allergen and environment has unique potential in asthma prophylaxis, because airway inflammation during infancy may be especially strategic for the development of remodelling. Current theories indicate that such interventions may require environmental modifications of multiple exposures. This is highlighted by the findings of WoODCOCK et al. [80], which showed that allergen-impermeable covers as a single intervention in the avoidance of exposure to HDM allergen were clinically ineffective in adult asthmatics. The current authors have found similar negative findings in a HDM avoidance study directed specifically at patients in whom HDM was clinically relevant [81]. 


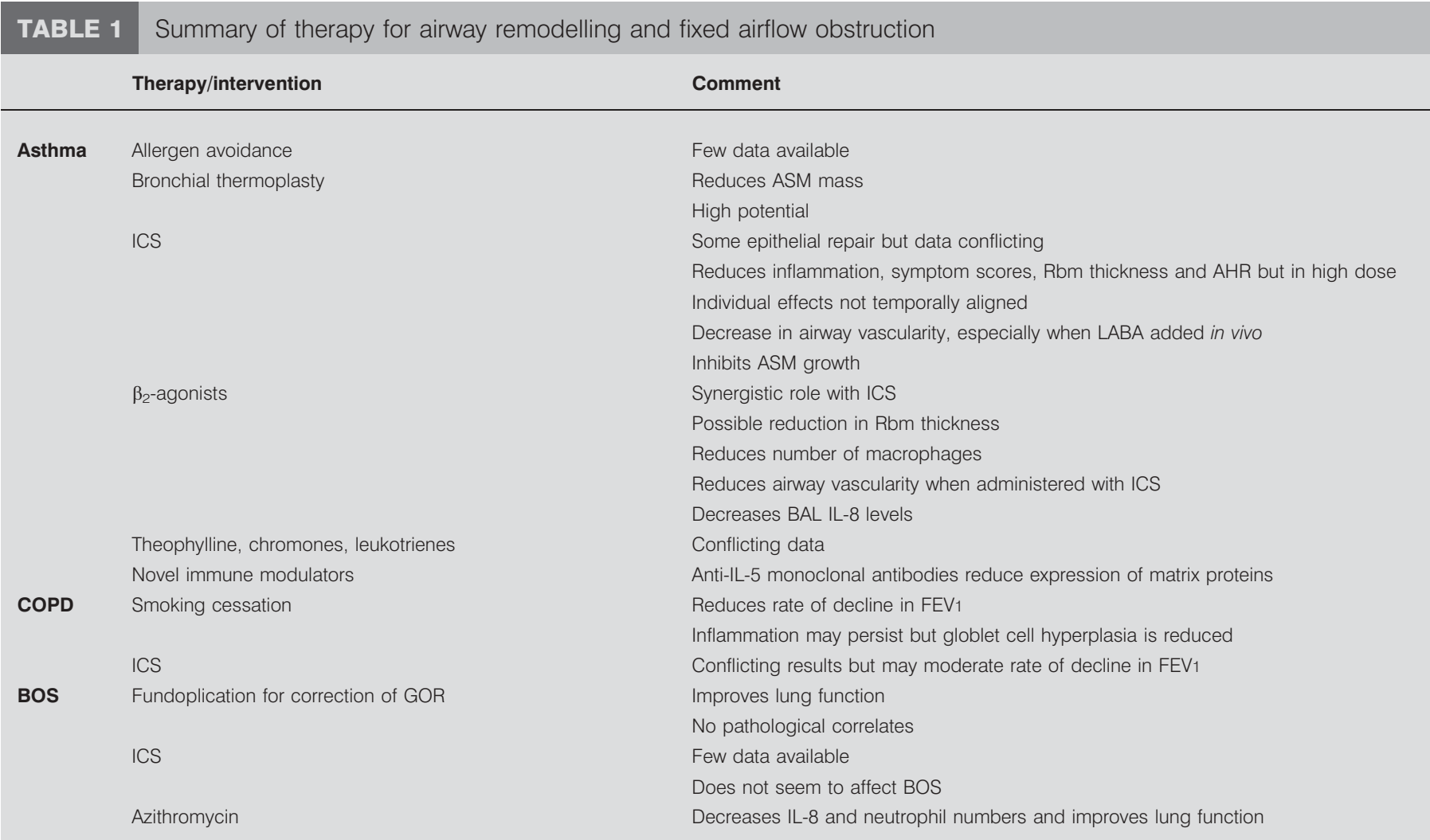

COPD: chronic obstructive pulmonary disease; BOS: bronchiolitis obliterans syndrome; ASM: airway smooth muscle; ICS: inhaled corticosteroids; Rbm: reticular basement membrane; AHR: airway hyperreactivity; LABA: long-acting $\beta$-agonist; BAL: bronchoalveolar lavage; IL: interleukin; FEV1: forced expiratory volume in one second; GOR: gastro-oesophageal reflux.

In contrast, there has been a report [82] that sustained avoidance of an occupational sensitiser over a period of 6 months could return subepithelial Rbm thickening to normal, suggesting that prolonged absence of asthmagenic stimuli can reverse remodelling. Interestingly, this reported improvement in remodelling occurred without parallel improvement in inflammation or eosinophil and mast cell degranulation, suggesting that these processes can be dissociated.

\section{Bronchial thermoplasty}

As mentioned previously, the aim of bronchial thermoplasty is to reduce ASM mass and, thereby, impair the airways capacity to contract. It has potential value in asthmatic patients who respond poorly to conventional pharmacological treatments. Limited data from eight humans scheduled for lung resections [83] and 16 subjects with mild-to-moderate asthma [84] showed that the procedure was safe, well tolerated and resulted in a reduction in ASM mass. The study also showed improved pre-bronchodilator FEV1 and reduced airway responsiveness to methacholine; these were maintained for up to 2 yrs following treatment. However, the long-term effects are not known. It is also unknown whether the inherent inability of this physical therapy to reach peripheral airways could reduce patient compliance with conventional pharmacological therapies, particularly if their symptoms improve. Ideally, trials should also include airway biopsy studies to assess the effect of thermoplasty on airway structural components [85].

\section{COPD}

\section{Smoking cessation}

The deleterious impact of smoking and the benefits of cessation on respiratory symptoms, lung function, AHR and inflammation have been thoroughly reviewed by WILLEMSE et al. [86]. Smoking is the main risk factor for the development of COPD [2] and cessation ameliorates excessive decline in lung function [18], implying that structural stabilisation occurs. Published histopathological studies are lacking in this area, a significant deficit given the scale of the COPD epidemic.

Indeed, data on airway remodelling in COPD are very scarce, with only cross-sectional studies reported to date. WRIGHT et al. [87] studied 97 patients undergoing thoracotomy and evaluated pulmonary function and airway structural changes. Patients who had stopped smoking had lung function closer to the nonsmoking group, but there was no apparent difference between current and ex-smokers in structural changes, which included increases in airway wall fibrosis in respiratory bronchioles and goblet cell metaplasia in small airways. It is possible that goblet cell hyperplasia at least may be partially reversible following smoking cessation, and that this may be a mechanism for the beneficial effect on decline of lung function. However, the limited available data also indicate that mucous 
gland hypertrophy and wall fibrosis are not affected by smoking cessation. Further prospective longitudinal studies of airway structural component changes in parallel with smoking cessation are required.

\section{BOS}

Fundoplication to correct gastro-oesophageal reflux

Gastro-oesophageal reflux (GOR) has been reported in a range of respiratory disorders, including asthma and COPD. This is often "silent", i.e. asymptomatic for clinical manifestations such as heart burn. GOR has been implicated as a possible mechanism of nonimmunological injury in lung transplantation and, indeed, allograft recipients have a number of risk factors for GOR [88]. Thus, lung allograft surgery causes significant damage to vagal innervation of the gastro-intestinal tract and the immunosuppressant drugs cyclosporine and tacrolimus reduce gastric motility. In addition, cough reflexes and mucociliary clearance, the normal defence mechanisms against aspiration, are attenuated [89]. Recently, it has been shown that the gastric acid protease pepsin is present in BAL samples from lung allografts, providing direct evidence of significant gastric aspiration in lung allografts [90]. A high clinical suspicion regarding the role of GOR has been raised by studies from lung transplantation programme at Duke University (Durham, NC, USA) [91]. They have also consistently shown objective evidence of GOR disease in the majority $(70 \%)$ of lung transplant recipients by oesophageal $\mathrm{pH}$ monitoring, and that this factor appeared to contribute to mortality and development of BOS. In a recently studied paediatric cohort of lung transplant recipients from Great Ormond Street Hospital (London, UK), all patients without surgical correction had objective evidence of reflux from positive $\mathrm{pH}$ studies [92]. Open trials of fundoplicative surgery have been carried out in lung transplant recipients with GOR and this has been shown to be associated with significant improvements in lung function. This implies that structural improvements in airway remodelling may have occurred but as yet there are no studies correlating pathological measurements, lung function and the effect of fundoplication, nor any prospective controlled studies of surgical intervention [91].

\section{Pharmacological Treatment}

\section{Asthma}

Corticosteroids

Corticosteroids provide mainstay treatment in asthma, as recently reviewed by BECKETT and HOWARTH [25]. More data on the long-term effects on clinical and physiological outcomes (such as FEV1) are required, but there is a lack of truly longterm and sufficiently detailed studies. However, this effort has started with recent bronchoscopic airway biopsy studies contributing to a better understanding of the potential for corticosteroids to alter remodelling. Such studies are most useful when correlated with physiological measurements [6]. Corticosteroid treatment in asthma may impact on several types of structural and (pro-)inflammatory cells and mediators in the airways that may be involved in the remodelling process. The relevant literature is reviewed hereafter, taking one tissue component at a time.

\section{Airway epithelium}

Several bronchoscopic biopsy studies have reported denudation of the epithelium as being characteristic of asthma, although this is likely to be an artefact of the sampling process [1]. The literature indicates that ICS treatment is associated with a decrease in BAL epithelial cell numbers in asthma, temporally in parallel with clinical improvements. This suggests normalisation of epithelial friability [25], i.e. that the poorly adhesive asthmatic epithelium is ICS responsive. However, the data available on the overall beneficial effects of corticosteroids to the epithelium in asthma is equivocal.

The epidermal growth factor (EGF) mediator family stimulates epithelial cell migration, proliferation and differentiation, and is a key mechanism of normal epithelial repair [93, 94]. This system may be defective in asthma. EGF receptor expression has been shown to be upregulated in the asthmatic epithelium and related to disease activity, but it was apparently not affected by ICS $[95,96]$. Therefore, the EGF signalling pathway does not appear to be downregulated by ICS. Rather paradoxically perhaps, increased expression of p21 (waf) cyclin-dependent kinase inhibitor, a marker of inhibited cell cycling and turnover, was also shown in asthmatic bronchial epithelium, but again was not affected by 8 weeks of treatment with ICS [97]. The asthmatic epithelium, therefore, may be locked into an aberrant repair phenotype with incomplete restitution, which may represent a key aspect of asthma pathophysiology and remodelling, an aspect which seems resistant to ICS based on the available data.

It has been suggested that corticosteroids can induce apoptosis of epithelial cells, but also in contrast that they can make the epithelium resistant to apoptotic stimuli [98]. Further work is clearly needed in this area to address the apparent contradictions in the literature regarding whether the effects of corticosteroids on the airway epithelium are, on balance, positive or not.

\section{Subepithelial Rbm thickening and lamina propria scarring}

LAITINEN et al. [99] showed that treatment with $400 \mu \mathrm{g}$ budesonide b.i.d. for $\leqslant 6$ weeks led to a decrease in subepithelial staining for the matrix protein tenascin. This component of Rbm thickening was also subsequently measured by LINDQVIST et al. [100] in a study comparing 16 weeks of inhaled FP $250 \mu \mathrm{g}$ b.i.d. with disodium cromoglycate $5 \mathrm{mg}$ q.i.d. and salmeterol $50 \mu \mathrm{g}$ b.i.d. In this case, there was a nonsignificant trend for a fall in tenascin thickness with ICS treatment. The work of SONT et al. [101] for the Asthma Management Project University Leiden (AMPUL) study group showed that when measurements of AHR were used to titrate levels of ICS therapy this led to a significant reduction in $\mathrm{Rbm}$ thickness after 24 months of treatment. Higher levels of ICS were required to optimise changes in AHR and remodelling compared with induction of symptom reduction alone. More recently, the current authors have evaluated the effects of $\leqslant 12$ months treatment with highdose $\left(1.5 \mathrm{mg} \cdot \mathrm{day}^{-1}\right) \mathrm{FP}$ in a "proof-of-concept" study. Following 3 months of treatment, BAL and biopsy inflammatory cell counts fell significantly, with no further ICS effect on inflammation after this treatment period. These changes in airway inflammation preceded a normalising effect on Rbm thickness and further improvement in AHR, which was observed at 12 months [102, 103]. The study strongly suggested that both 
airway inflammation and remodelling contribute to AHR, but that long-term treatment is required in adults with mild asthma to reverse some of the changes of remodelling.

Overall, these observations indicate that airway inflammation, $\mathrm{Rbm}$ thickening and AHR in asthma are interrelated and improved by ICS therapy, but that this therapeutic effect occurs on different timescales and may have differing doseresponse relationships. As in some of the animal studies, more aggressive ICS therapy may well be necessary to improve aspects of remodelling and airway damage. The data obtained by the current authors support the need for early but also longterm intervention with ICS in asthma to achieve maximum potential benefits. As in the AMPUL study [101], these newer data also indicated that ICS effects on remodelling might need to be monitored with serial AHR rather than simply lung function, symptom scoring or surrogates of airway inflammation, e.g. sputum eosinophils or exhaled nitric oxide levels. The potential for different aspects of airway scarring processes in asthma to have different responses and timescales to steroid therapy has also been suggested by CHAKIR et al. [104].

Further prospective studies are clearly needed to clarify basic questions, such as whether Rbm thickening may be a protective response to injury [25] and hence potentially beneficial in acute attacks [10]. The need for better insights was emphasised by the current follow-up analysis of the AMPUL cohort in which 32 out of the original 45 patients had repeat airway biopsies after 7.5 yrs [105]. In this case, the decline in post-bronchodilator FEV1 as a surrogate of fixed structural change was correlated with airway inflammatory parameters and Rbm thickening. The only significant association was weak, occurring with initial airway CD8 lymphocyte count but not Rbm thickening. This potentially important study did not report correction for multiple statistical tests. CD8 cells are more commonly associated in cross-sectional studies with smoking-related COPD; however, it is of interest that in the current authors' longitudinal study of BOS in lung allografts, a multivariate model also showed that airway biopsy CD8 counts were associated with BOS and chronic loss of lung function [106]. This may implicate CD8 lymphocytes as a common factor in airway remodelling.

\section{Vascularity}

In a cross-sectional study [107], the current authors' group has shown that patients who received $\geqslant 800 \mu \mathrm{g} \cdot \mathrm{day}^{-1}$ of the ICS beclomethasone dipropionate (BDP) had a reduced number of subepithelial airway vessels compared with patients not on ICS and those receiving $\leqslant 500 \mu \mathrm{g} \cdot$ day $^{-1}$ BDP. This emphasised a requirement for longitudinal studies. The effect of 6 weeks of treatment with low- $\left(200 \mu \mathrm{g} \cdot \mathrm{day}^{-1}\right)$ and high-dose $\left(1,000 \mu \mathrm{g} \cdot \mathrm{day}^{-1}\right)$ inhaled FP were examined in an intervention study by CHETTA et al. [108]. Paired biopsies were available from a total of 16 subjects with mild asthma. Inflammatory cell counts, AHR to methacholine and symptom scores were improved by both treatments but the number of vessels, vascular area and Rbm thickness decreased only after high-dose ICS. This study did not have a placebo arm, but again suggested that modulation of airway remodelling might require more intensive and perhaps longer-term treatment than is required to resolve airway inflammation and clinical symptoms. HosHINO et al. [109] showed a decrease in airway vascularity following $800 \mu \mathrm{g}$ BDP for 6 months in a placebocontrolled trial of 28 asthmatics.

\section{Airway smooth muscle}

Pre-incubation of ASM cells with corticosteroids inhibited growth factor-induced migration and enabled an inhibitory effect of salmeterol on cell migration [110]. These data suggested that corticosteroids may inhibit the putative expansion of airway myofibroblast/fibroblast populations in asthma. However, extrapolation to the more complex in vivo situation, where cell migration will be influenced by the surrounding matrix, cell density and cytokine milieu, is speculative at present. Clinico-pathological correlation biopsy studies are required to follow-up such findings, which are currently limited to ex vivo cell culture studies.

\section{$\beta_{2}$-agonists}

There are few studies on the effects of $\beta_{2}$-agonists on airway remodelling in asthma. AltrajA et al. [111] studied 32 asthmatics, who showed a significant fall in tenascin thickness below the true basement membrane following 12 weeks of treatment with the inhaled SABA salbutamol (200 $\mu$ g q.i.d.). This was also accompanied by a fall in biopsy macrophages. However, the study was uncontrolled and there was no decrease in subepithelial collagen, but it did suggest a possible modulating role for regular $\beta$-agonists on aspects of remodelling.

There are limited data on the effect of LABAs on airway inflammation with even fewer studies assessing possible effects on airway remodelling in asthma with direct airway sampling. This is in contrast to more extensive in vitro data, indicating a possible synergistic role of LABA and ICS. The current authors investigated 45 symptomatic asthmatics and 28 normal subjects without asthma and confirmed the consistent finding of increased subepithelial airway vascularity in asthma. The asthmatics were symptomatic and receiving low-dose ICS. There was no significant effect on airway vascularity of 3 months additional treatment with FP, equivalent to doubling the ICS dose. In contrast, adding salmeterol $(50 \mu \mathrm{g}$ b.i.d.) was associated with a significant $(\sim 20 \%)$ decrease in vessel density [32]. In a separate publication from studies of the same patient group it was also shown that LABA therapy was associated with a decrease in BAL IL-8 (CXC chemokine ligand 8) levels [33]. IL-8 is a documented potential driver of angiogenesis, in addition to its action as a neutrophil chemoattractant. Overall, therefore, these data suggest a possible advantageous effect of LABA, at least in combination with ICS, on airway vascularity and pro-angiogenic influences.

In contrast, LINDQVIST et al. [100] showed that there was no effect of $50 \mu \mathrm{g}$ salmeterol b.i.d. alone on subepithelial tenascin or airway eosinophils. The study was conducted in newly diagnosed asthmatics rather than the population of asthmatics in the current authors' positive studies, who had symptoms on the background of maintenance ICS [32, 33]. Collectively, the available data emphasise that in future long-term studies, patient selection will be important, as well as whether LABA is given in combination with ICS or not.

\section{Theophylline, chromones and LT modifiers}

There are few available bronchocopic studies performed on asthmatics before and after these therapies, in spite of their 
widespread use. The studies available report conflicting data on possible anti-remodelling properties with these agents. There were no effects of 12 weeks treatment with nedocromil sodium $4 \mathrm{mg}$ q.i.d. on subepithelial tenascin staining [111] and more recently it was found that $5 \mathrm{mg}$ q.i.d. disodium cromoglycate for 16 weeks had no effect on subepithelial tenascin staining [100]. Longer-term studies on the effect of these therapies on airway remodelling have not been conducted, but again, need to be.

\section{Anti-immunoglobulin E therapy}

Omalizumab, a humanised anti-immunoglobulin (Ig)E monoclonal antibody, has been shown to be effective in asthma treatment, but perhaps less so than might be expected from the profound diminution of $\operatorname{IgE}$ that occurs and the expectation of success predicated on the theoretical importance of $\operatorname{IgE}$ in driving the asthmagenic process(es) $[112,113]$. It might be that non-IgE and non-mast cell processes in which T-cells respond directly to presented allergen oligopeptides are more important in driving chronic asthma pathology than has previously been assumed [114]. On this basis, with only partial clinical amelioration of asthma reactions to allergen, it will be interesting to see whether anti-IgE therapy does affect airway remodelling. However, such data are not yet available.

\section{Anti-cytokine/cytokine and other novel anti-inflammatory therapies} The effects of the infusion of a humanised anti-IL-5 monoclonal antibody were investigated in 24 atopic asthmatics in a randomised, placebo-controlled study by FLOOD-PAGE et al. [115], which showed a significantly reduced expression of the matrix proteins tenascin, lumican and procollagen III in the bronchial mucosal Rbm when compared with placebo. The anti-IL-5 treatment was also associated with a significant reduction in the numbers of airway eosinophils expressing mRNA for TGF- $\beta$ and reduction in BAL fluid TGF- $\beta$, indicating a potential mechanism for this modulation of airway remodelling. In contrast, however, an earlier study [116] indicated that there were no significant changes in AHR, FEV1 or peak expiratory flow with anti-IL-5 therapy. Once more, such findings emphasise the need to fully integrate the effects of airway remodelling with clinical outcomes and physiological evaluations [6].

Similarly, recombinant IL-12 seems, from preliminary experiments, to be therapeutically disappointing in asthma. Although it had anti-eosinophil activity, it did not affect the clinical or physiological effects of allergen challenge and had significant side-effects [113]. Nebulised recombinant IL-4 receptor as an IL-4 antagonist also seems ineffective as chronic therapy [113]. There are no data available yet on airway remodelling with these agents.

Suppression of tumour necrosis factor (TNF) in the airway is currently more promising therapeutically, although available data are conflicting. In mild-to-moderate asthma (presumably on low-dose or no corticosteroid), the injection of etanercept (a soluble TNF- $\alpha$ receptor-IgG $\mathrm{F}_{1} \mathrm{Fc}$ fusion protein) was demonstrated to reach airway lining fluid, but had no demonstrable cellular effect on segmental allergen challenge, except for paradoxically increasing the levels of Th2 cytokine IL-4 in the airway [117]. Indeed, this is consistent with a TNF receptordeficient mouse model, where the airway effects of allergen challenge were found to be generally increased [118]. Thus, TNF- $\alpha$ inhibition in asthma may not necessarily be a good thing. Even so, a recent preliminary clinical study has suggested that at least in severe, corticosteroid-dependent asthma TNF may be a significant active pathogenic mediator, with 12 weeks of therapy with etanercept having an apparent positive effect on asthma symptoms, lung function and AHR, but actually without a significant effect on airway inflammation [119]. These results need confirmation in a conventional randomised controlled trial, preferably to include information on remodelling, which is not yet available for anti-TNF therapy. Whether corticosteroids themselves are anti- or proTNF production in asthma also needs further investigation.

There are many potential ways of modulating the immune system and airway inflammation and thus, it is hoped, airway remodelling. A number of exciting novel therapeutic agents are being developed for trial in asthma and allergic airway disease $[113,120]$. For example, there are already preliminary data that an allergen-ISS-ODN conjugate vaccination is possible and apparently well tolerated when administered topically in rhinitis, and also that an anti-sense oligonucleotide blocks IL-4 mRNA translation in downregulating allergic inflammation in ex vivo human upper airway biopsies. The next few years are likely to see such compounds being trialled clinically in chronic asthma. Such studies need to produce data not only on airway inflammation, but also on airway remodelling, and in this manner gain further insight into the therapeutic profile and potential side-effects, as these drugs also have potential for harm [117]. In particular, if immune modulation skews the inflammatory response too much towards Th1 reactivity, then there is the danger of alleviating asthma at the expense of making patients more vulnerable to autoimmune diseases, such as multiple sclerosis, diabetes or Crohn's disease. The need for substantial care has been emphasised [69].

\section{COPD}

There has been little, if any, longitudinal work published to date using endobronchial biopsies. This should be a clear priority for further clinical research.

\section{BOS}

\section{Corticosteroids}

Inhaled BDP $800 \mu \mathrm{g} \cdot \mathrm{day}^{-1}$, in addition to maintenance oral steroid therapy, had no effect on $\mathrm{Rbm}$ thickening over a period of 3 months [34]. This confirmed an earlier steroid trial evaluation of FP $1.5 \mathrm{mg} \cdot \mathrm{day}^{-1}$ for $\leqslant 1$ year, which also showed no obvious benefits [121].

In lung allografts, there is evidence of epithelial mesenchymal interaction $[35,36]$. There are no treatment intervention data on EMT but the data available have been collected in allografts treated with aggressive immunosuppressives, including oral steroids, which might suggest that EMT is corticosteroid resistant.

\section{Azithromycin}

Recent pilot studies of macrolide antibiotics in BOS have shown clinical benefit in some individuals [122-124] and it was suggested that airway neutrophils and IL-8 levels are decreased by this therapy. In an extended case series of 20 
patients, $50 \%$ of them had improved lung function following 2-3 months of treatment with azithromycin, with a median $110 \mathrm{~mL}$ increase in FEV1 [122]. These noncontrolled findings indicate that airway structural improvements may have occurred and this is currently another question requiring urgent investigation, given the devastating morbidity and mortality associated with BOS. At the moment, it is not known whether the effects of azithromycin are due to direct antiinflammatory properties or secondary to antibiotic action(s) on microbial contamination of the airways.

\section{CONCLUSIONS}

This review has focused on factors that can influence airway remodelling occurring as part of, as a consequence of, or in parallel with, inflammatory airway diseases. The data available include: empirical observations based on the assumption that loss of lung function with development of nonbronchodilator responsive fixed airflow obstruction equates to airway damage and structural change; animal models of asthma and irritant-induced chronic obstructive pulmonary disease; and bronchoscopic studies in humans with chronic inflammatory airway diseases, in whom biopsies of the airways can be used to directly sample the airway wall and describe in considerable detail the histological alterations that represent these structural changes. The latter studies include those with repeat airway sampling to monitor therapeutic interventions and those with relatively sophisticated pathophysiological and clinical correlations. The best of these analyses are multi-faceted, exploring a number of features of remodelling, such as epithelial changes, scar collagen and other abnormal matrix protein depositions, and changes in vascularity. However, observation of changes in airway smooth muscle or other structures at a depth $>200 \mu \mathrm{m}$ is not possible with endobronchial sampling.

Reviewing the literature has highlighted a number of therapeutic questions that need urgent attention (table 2).
1) Are there any potentially negative implications in aggressively treating those parts of the remodelling process that increase airway stiffness? It has been suggested that these changes may prevent excessive narrowing of the airways due to intense bronchoconstriction, e.g. in severe asthma attacks. There is also the potential systemic morbidity in pursuing the high-dose, long-term therapy with inhaled corticosteroids that may be necessary to have maximal impact on remodelling processes.

2) Are the effects of long-acting $\beta$-agonists on remodelling positive or negative? Data are currently contradictory.

3) Does the long-acting anticholinergic tiotropium have major positive potential benefits on remodelling as proposed from animal studies? This could appreciably change the positioning of this drug in chronic respiratory disease (especially to include asthma), if these findings are substantiated in humans.

4) Can the apparently dramatic effects on airway remodelling induced in animal models by chromones and leukotriene antagonists be replicated in human studies? A problem might be the need to administer treatment before environmental insult (comparable to the allergen in the animal models studied), i.e. prophylactically.

5) Can epithelial dysfunction associated with remodelling be reversed by therapeutic intervention? If, as is widely proposed, an aberrant repair-mode phenotype of the epithelium is a fundamental driving force to continued long-term structural and functional change in the airways, this is a matter of major importance.

6) Are the apparent effects of azithromycin in bronchiolitis obliterans syndrome-related to anti-inflammatory rather than antimicrobial effects? If so, can it reverse remodelling changes in other airway diseases?

\section{TABLE 2 Suggested future studies}

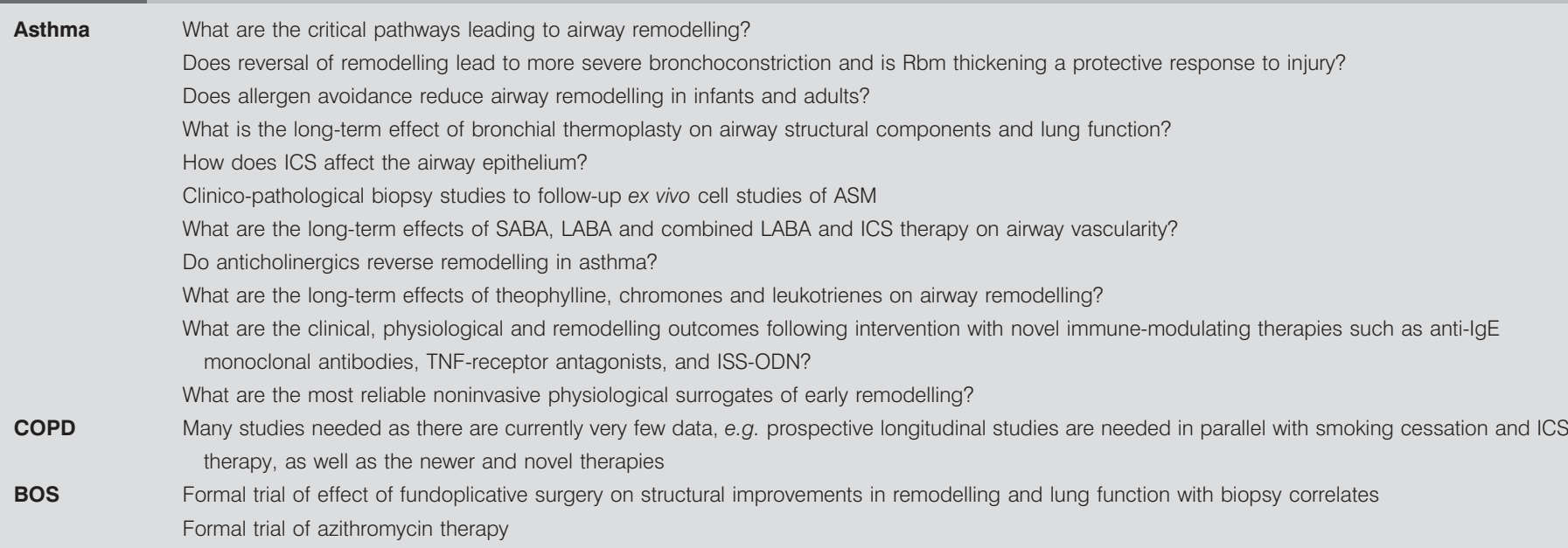


7) Much more work is needed on the pathology and therapeutics of remodelling in chronic obstructive pulmonary disease.

8) As newer immune-modulating drugs are trialled, airway biopsies need to be obtained to investigate how remodelling is affected, as well as merely detailing changes in cellular chronic inflammation.

In spite of the difficulties inherent in invasive studies in animals and particularly in patients, a great deal has been learnt in this area of review over the past decade. This applies especially to asthma and, to a lesser extent, bronchiolitis obliterans syndrome following lung transplantation. Chronic obstructive pulmonary disease has been a rather orphan area for intense research and research funding support, and this is very much reflected in the paucity of data on remodelling in this condition, and how it might respond to therapy. There is a major gap here which needs filling.

\section{REFERENCES}

1 Jeffery PK. Remodeling in asthma and chronic obstructive lung disease. Am J Respir Crit Care Med 2001; 164: S28-S38.

2 Hogg JC, Chu F, Utokaparch S, et al. The nature of smallairway obstruction in chronic obstructive pulmonary disease. N Engl J Med 2004; 350: 2645-2653.

3 Banner NR, Polak JM, Yacoub MH. Lung Transplantation. Cambridge, Cambridge University Press, 2004.

4 Davies DE, Wicks J, Powell RM, Puddicombe SM, Holgate ST. Airway remodeling in asthma: new insights. J Allergy Clin Immunol 2003; 111: 215-225.

5 Lange P, Parner J, Vestbo J, Schnohr P, Jensen G. 15-year follow-up study of ventilatory function in adults with asthma. N Engl J Med 1998; 339: 1194-1200.

6 Fish JE, Peters SP. Airway remodeling and persistent airway obstruction in asthma. J Allergy Clin Immunol 1999; 104: 509-516.

7 Elias JA. Airway remodeling in asthma. Unanswered questions. Am J Respir Crit Care Med 2000; 161: S168-S171.

8 Pedersen S. Why does airway inflammation persist? Is it failure to treat early? Am J Respir Crit Care Med 2000; 161: S182-S185.

9 Vignola AM, Kips J, Bousquet J. Tissue remodeling as a feature of persistent asthma. J Allergy Clin Immunol 2000; 105: 1041-1053.

10 Bai TR, Knight DA. Structural changes in the airways in asthma: observations and consequences. Clin Sci (Lond) 2005; 108: 463-477.

11 Sears MR, Greene JM, Willan AR, et al. A longitudinal, population-based, cohort study of childhood asthma followed to adulthood. N Engl J Med 2003; 349: 1414-1422.

12 Zeiger RS, Dawson C, Weiss S. Relationships between duration of asthma and asthma severity among children in the Childhood Asthma Management Program (CAMP). J Allergy Clin Immunol 1999; 103: 376-387.

13 Covar RA, Spahn JD, Murphy JR, Szefler SJ, for the Childhood Asthma Management Program Research Group. Progression of asthma measured by lung function in the childhood asthma management program. Am J Respir Crit Care Med 2004; 170: 234-241.
14 Apostol GG, Jacobs DR Jr, Tsai AW, et al. Early life factors contribute to the decrease in lung function between ages 18 and 40: the Coronary Artery Risk Development in Young Adults study. Am J Respir Crit Care Med 2002; 166: 166-172.

15 Ulrik CS, Lange P. Decline of lung function in adults with bronchial asthma. Am J Respir Crit Care Med 1994; 150: 629-634.

16 Haahtela T, Jarvinen K, Kava T, et al. Effects of reducing or discontinuing inhaled budesonide in patients with mild asthma. N Engl J Med 1994; 331: 700-705.

17 Pauwels RA, Pedersen S, Busse WW, et al. Early intervention with budesonide in mild persistent asthma: a randomized, double-blind trial. Lancet 2003; 361: 1071-1076.

18 Omori H, Nonami Y, Morimoto Y. Effect of smoking on FEV1 decline in a cross-sectional and longitudinal study of a large cohort of Japanese males. Respirology 2005; 10: 464-469.

19 Highland KB, Strange C, Heffner JE. Long-term effects of inhaled corticosteroid on FEV1 in patients with chronic obstructive pulmonary disease. A meta-analysis. Ann Intern Med 2003; 138: 969-973.

20 Sutherland ER, Allmers H, Ayas NT, Venn AJ, Martin RJ. Inhaled corticosteroids reduce the progression of airflow limitation in chronic obstructive pulmonary disease: a meta-analysis. Thorax 2003; 58: 937-941.

21 Ward C, Johns DP, Bish R, et al. Reduced airway distensibility, fixed airflow limitation, and airway wall remodeling in asthma. Am J Respir Crit Care Med 2001; 164: 1718-1721.

22 Huber H, Koessler KK. The pathology of bronchial asthma. Arch Intern Med 1922; 30: 689-760.

23 Houston JC, De Navasquez S, Trounce JR. A clinical and pathological study of fatal cases of status asthmaticus. Thorax 1953; 8: 207-213.

24 Boser SR, Park H, Perry SF, Menache MG, Green FH. Fractal geometry of airway remodeling in human asthma. Am J Respir Crit Care Med 2005; 172: 817-823.

25 Beckett PA, Howarth PH. Pharmacotherapy and airway remodelling in asthma? Thorax 2003; 58: 163-174.

26 Hogg JC. Pathophysiology of airflow limitation in chronic obstructive pulmonary disease. Lancet 2004; 364: 709-721.

27 Boehler A, Estenne M. Post-transplant bronchiolitis obliterans. Eur Respir J 2003; 22: 1007-1018.

28 Estenne M, Hertz MI. Bronchiolitis obliterans after human lung transplantation. Am J Respir Crit Care Med 2002; 166: 440-444.

29 Zheng L, Ward C, Snell GI, et al. Scar collagen deposition in the airways of allografts of lung transplant recipients. Am J Respir Crit Care Med 1997; 155: 2072-2077.

30 Zheng L, Orsida BE, Ward C, et al. Airway vascular changes in lung allograft recipients. J Heart Lung Transplant 1999; 18: 231-238.

31 Belperio JA, Keane MP, Burdick MD, et al. Role of CXCR2/CXCR2 ligands in vascular remodeling during bronchiolitis obliterans syndrome. J Clin Invest 2005; 115: 1150-1162.

32 Orsida BE, Ward C, Li X, et al. Effect of a long-acting $\beta_{2^{-}}$ agonist over three months on airway wall vascular remodeling in asthma. Am J Respir Crit Care Med 2001; 164: 117-121. 
33 Reid DW, Ward C, Wang N, et al. Possible antiinflammatory effect of salmeterol against interleukin-8 and neutrophil activation in asthma in vivo. Eur Respir J 2003; 21: 994-999.

34 Ward C, De Soyza A, Fisher AJ, Pritchard G, Forrest IA, Corris PA. Reticular basement membrane thickening in airways of lung transplant recipients is not affected by inhaled corticosteroids. Clin Exp Allergy 2004; 34: 1905-1909.

35 Ward C, Forrest IA, Murphy DM, et al. Phenotype of airway epithelial cells suggests epithelial to mesenchymal cell transition in clinically stable lung transplant recipients. Thorax 2005; 60: 865-871.

36 Ward C, Robertson H, Forrest IA, et al. Hypothesis: epithelial-to-mesenchymal transition is a common cause of chronic allograft failure. Transplant Proc 2005; 37: 977-980.

37 Kariyawasam HH, Robinson DS. Airway remodelling in asthma: models and supermodels? Clin Exp Allergy 2005; 35: 117-121.

38 Shinagawa K, Kojima M. Mouse model of airway remodeling: strain differences. Am J Respir Crit Care Med 2003; 168: 959-967.

39 Kumar RK, Herbert C, Kasper M. Reversibility of airway inflammation and remodelling following cessation of antigenic challenge in a model of chronic asthma. Clin Exp Allergy 2004; 34: 1796-1802.

40 Leigh R, Ellis R, Wattie JN, et al. Type 2 cytokines in the pathogenesis of sustained airway dysfunction and airway remodeling in mice. Am J Respir Crit Care Med 2004; 169: 860-867.

41 Leigh R, Ellis R, Wattie J, Donaldson DD, Inman MD. Is interleukin-13 critical in maintaining airway hyperresponsiveness in allergen-challenged mice? Am J Respir Crit Care Med 2004; 170: 851-856.

42 Leigh R, Southam DS, Ellis R, et al. T cell-mediated inflammation does not contribute to the maintenance of airway dysfunction in mice. I Appl Physiol 2004; 97: 2258-2265.

43 Cho JY, Miller M, Baek KJ, et al. Inhibition of airway remodeling in IL-5-deficient mice. J Clin Invest 2004; 113: 551-560.

44 Humbles AA, Lloyd CM, McMillan SJ, et al. A critical role for eosinophils in allergic airways remodeling. Science 2004; 305: 1776-1779.

45 Blyth DI, Wharton TF, Pedrick MS, Savage TJ, Sanjar S. Airway subepithelial fibrosis in a murine model of atopic asthma: suppression by dexamethasone or anti-interleukin5 antibody. Am J Respir Cell Mol Biol 2000; 23: 241-246.

46 Kumar RK, Herbert C, Foster PS. Expression of growth factors by airway epithelial cells in a model of chronic asthma: regulation and relationship to subepithelial fibrosis. Clin Exp Allergy 2004; 34: 567-575.

47 Johnson JR, Wiley RE, Fattouh R, et al. Continuous exposure to house dust mite elicits chronic airway inflammation and structural remodeling. Am J Respir Crit Care Med 2004; 169: 378-385.

48 Snibson KJ, Bischoff RJ, Slocombe RF, Meeusen EN. Airway remodelling and inflammation in sheep lungs after chronic airway challenge with house dust mite. Clin Exp Allergy 2005; 35: 146-152.

49 Tran MU, Weir AJ, Fanucchi MV, et al. Smooth muscle hypertrophy in distal airways of sensitized infant rhesus monkeys exposed to house dust mite allergen. Clin Exp Allergy 2004; 34: 1627-1633.

50 Tanaka H, Masuda T, Tokuoka S, et al. Time course study on the development of allergen-induced airway remodeling in mice: the effect of allergen avoidance on established airway remodeling. Inflamm Res 2002; 51: 307-316.

51 Evans MJ, Fanucchi MV, Baker GL, et al. The remodelled tracheal basement membrane zone of infant rhesus monkeys after 6 months of recovery. Clin Exp Allergy 2004; 34: 1131-1136.

52 Danek CJ, Lombard CM, Dungworth DL, et al. Reduction in airway hyperresponsiveness to methacholine by the application of RF energy in dogs. J Appl Physiol 2004; 97: 1946-1953.

53 Brown RH, Wizeman W, Danek C, Mitzner W. In vivo evaluation of the effectiveness of bronchial thermoplasty with computed tomography. J Appl Physiol 2005; 98: 1603-1606.

54 Christie PE, Jonas M, Tsai CH, Chi EY, Henderson WR Jr. Increase in laminin expression in allergic airway remodelling and decrease by dexamethasone. Eur Respir J 2004; 24: 107-115.

55 Vanacker NJ, Palmans E, Kips JC, Pauwels RA. Fluticasone inhibits but does not reverse allergeninduced structural airway changes. Am J Respir Crit Care Med 2001; 163: 674-679.

56 Vanacker NJ, Palmans E, Pauwels RA, Kips JC. Doserelated effect of inhaled fluticasone on allergen-induced airway changes in rats. Eur Respir J 2002; 20: 873-879.

57 Walters JA, Wood-Baker R, Walters EH. Long-acting $\beta_{2^{-}}$ agonists in asthma: an overview of Cochrane systematic reviews. Respir Med 2005; 99: 384-395.

58 Vanacker NJ, Palmans E, Pauwels RA, Kips JC. Effect of combining salmeterol and fluticasone on the progression of airway remodeling. Am J Respir Crit Care Med 2002; 166: $1128-1134$.

59 Walters EH, Walters J. Inhaled short acting $\beta_{2}$-agonist use in chronic asthma: regular versus as needed treatment. Cochrane Database Syst Rev 2003; CD001285.

60 Kamachi A, Munakata M, Nasuhara Y, et al. Enhancement of goblet cell hyperplasia and airway hyperresponsiveness by salbutamol in a rat model of atopic asthma. Thorax 2001; 56: 19-24.

61 Kumar RK, Herbert C, Thomas PS, et al. Inhibition of inflammation and remodeling by roflumilast and dexamethasone in murine chronic asthma. J Pharmacol Exp Ther 2003; 307: 349-355.

62 Gosens R, Bos IS, Zaagsma J, Meurs H. Protective effects of tiotropium bromide in the progression of airway smooth muscle remodeling. Am J Respir Crit Care Med 2005; 171: 1096-1102.

63 Hoshino M. Impact of inhaled corticosteroids and leukotriene receptor antagonists on airway remodeling. Clin Rev Allergy Immunol 2004; 27: 59-64.

64 Henderson WR Jr, Tang LO, Chu SJ, et al. A role for cysteinyl leukotrienes in airway remodeling in a mouse asthma model. Am J Respir Crit Care Med 2002; 165: 108-116.

65 Wang CG, Du T, Xu LJ, Martin JG. Role of leukotriene D4 in allergen-induced increases in airway smooth muscle in the rat. Am Rev Respir Dis 1993; 148: 413-417. 
66 Salmon M, Walsh DA, Huang TJ, et al. Involvement of cysteinyl leukotrienes in airway smooth muscle cell DNA synthesis after repeated allergen exposure in sensitized Brown Norway rats. Br J Pharmacol 1999; 127: 1151-1158.

67 Vargaftig BB, Singer M. Leukotrienes mediate murine bronchopulmonary hyperreactivity, inflammation, and part of mucosal metaplasia and tissue injury induced by recombinant murine interleukin-13. Am J Respir Cell Mol Biol 2003; 28: 410-419.

68 Du T, Sapienza S, Wang CG, et al. Effect of nedocromil sodium on allergen-induced airway responses and changes in the quantity of airway smooth muscle in rats. J Allergy Clin Immunol 1996; 98: 400-407.

69 Silverman ES, Drazen JM. Immunostimulatory DNA for asthma: better than eating dirt. Am J Respir Cell Mol Biol 2003; 28: 645-647.

70 Ikeda RK, Nayar J, Cho JY, et al. Resolution of airway inflammation following ovalbumin inhalation: comparison of ISS DNA and corticosteroids. Am J Respir Cell Mol Biol 2003; 28: 655-663.

71 Jain VV, Kitagaki K, Businga T, et al. CpG-oligodeoxynucleotides inhibit airway remodeling in a murine model of chronic asthma. J Allergy Clin Immunol 2002; 110: 867872.

72 Cho JY, Miller M, Baek KJ, et al. Immunostimulatory DNA inhibits transforming growth factor-beta expression and airway remodeling. Am J Respir Cell Mol Biol 2004; 30: 651-661.

73 Fanucchi MV, Schelegle ES, Baker GL, et al. Immunostimulatory oligonucleotides attenuate airways remodeling in allergic monkeys. Am J Respir Crit Care Med 2004; 170: 1153-1157.

74 Brightling CE, Bradding $\mathrm{P}$, Symon FA, Holgate ST, Wardlow AJ, Pavord ID. Mast-cell infiltration of airway smooth muscle in asthma. $N$ Engl J Med 2002; 346: 1699-1705.

75 Matheson MC, Benke G, Raven J, et al. Biological dust exposure in the workplace is a risk factor for chronic obstructive pulmonary disease. Thorax 2005; 60: 645-651.

76 Groneberg DA, Chung KF. Models of chronic obstructive pulmonary disease. Respir Res 2004; 5: 18-33.

77 Nikula KJ, Green FH. Animal models of chronic bronchitis and their relevance to studies of particleinduced disease. Inhal Toxicol 2000; 12: Suppl. 4, 123-153.

78 Hele D. First Siena International Conference on animal models of chronic obstructive pulmonary disease, Certosa di Pontignana, University of Siena, Italy, September 30-October 2, 2001. Respir Res 2002; 3: 12.

79 Holt PG, Upham JW, Sly PD. Contemporaneous maturation of immunologic and respiratory functions during early childhood: implications for development of asthma prevention strategies. J Allergy Clin Immunol 2005; 116: 16-24.

80 Woodcock A, Forster L, Matthews E, et al. Control of exposure to mite allergen and allergen-impermeable bed covers for adults with asthma. N Engl J Med 2003; 349: 225-236.

81 Dharmage S, Walters EH, Thien F, et al. Encasement of bedding does not improve asthma in atopic adult asthmatics. Int Arch Allergy Immunol 2006; 139: 132-138.
82 Saetta M, Maestrelli P, Di Stefano A, et al. Effect of cessation of exposure to toluene diisocyanate (TDI) on bronchial mucosa of subjects with TDI-induced asthma. Am Rev Respir Dis 1992; 145: 169-174.

83 Miller JD, Cox G, Vincic L, Lombard CM, Loomas BE, Danek CJ. A prospective feasibility study of bronchial thermoplasty in the human airway. Chest 2005; 127: 1999-2006.

84 Cox G, Miller JD, McWilliams A, Fitzgerald JM, Lam S. Bronchial thermoplasty for asthma. Am J Respir Crit Care Med 2006; 173: 965-969.

85 Bel EH. "Hot stuff": bronchial thermoplasty for asthma. Am J Respir Crit Care Med 2006; 173: 941-942.

86 Willemse BW, Postma DS, Timens W, ten Hacken NH. The impact of smoking cessation on respiratory symptoms, lung function, airway hyperresponsiveness and inflammation. Eur Respir J 2004; 23: 464-476.

87 Wright JL, Lawson LM, Pare PD, Wiggs BJ, Kennedy S, Hogg JC. Morphology of peripheral airways in current smokers and ex-smokers. Am Rev Respir Dis 1983; 127: 474-477.

88 Au J, Hawkins T, Venables C, et al. Upper gastrointestinal dysmotility in heart-lung transplant recipients. Ann Thorac Surg 1993; 55: 94-97.

89 Veale D, Glasper PN, Gascoigne A, Dark JH, Gibson GJ, Corris PA. Ciliary beat frequency in transplanted lungs. Thorax 1993; 48: 629-631.

90 Ward C, Forrest IA, Brownlee IA, et al. Pepsin like activity in bronchoalveolar lavage fluid is suggestive of gastric aspiration in lung allografts. Thorax 2005; 60: 872-874.

91 Cantu E 3rd, Appel JZ 3rd, Hartwig MG, et al. J. Maxwell Chamberlain Memorial Paper. Early fundoplication prevents chronic allograft dysfunction in patients with gastroesophageal reflux disease. Ann Thorac Surg 2004; 78: 1142-1151.

92 Benden C, Aurora P, Curry J, Whitmore P, Priestley L, Elliott MJ. High prevalence of gastroesophageal reflux in children after lung transplantation. Pediatr Pulmonol 2005; 40: 68-71.

93 Klapper LN, Kirschbaum MH, Sela M, Yarden Y. Biochemical and clinical implications of the ErbB/HER signaling network of growth factor receptors. Adv Cancer Res 2000; 77: 25-79.

94 Yarden Y. The EGFR family and its ligands in human cancer signalling mechanisms and therapeutic opportunities. Eur J Cancer 2001; 37: Suppl. 4, S3-S8.

95 Puddicombe SM, Polosa R, Richter A, et al. Involvement of the epidermal growth factor receptor in epithelial repair in asthma. FASEB J 2000; 14: 1362-1374.

96 Polosa R, Puddicombe SM, Krishna MT, et al. Expression of c-erbB receptors and ligands in the bronchial epithelium of asthmatic subjects. J Allergy Clin Immunol 2002; 109: 75-81.

97 Puddicombe SM, Torres-Lozano C, Richter A, et al. Increased expression of p21(waf) cyclin-dependent kinase inhibitor in asthmatic bronchial epithelium. Am J Respir Cell Mol Biol 2003; 28: 61-68.

98 Pelaia G, Cuda G, Vatrella A, et al. Effects of transforming growth factor- $\beta$ and budesonide on mitogen-activated protein kinase activation and apoptosis in airway epithelial cells. Am J Respir Cell Mol Biol 2003; 29: 12-18. 
99 Laitinen A, Altraja A, Kampe M, Linden M, Virtanen I, Laitinen LA. Tenascin is increased in airway basement membrane of asthmatics and decreased by an inhaled steroid. Am J Respir Crit Care Med 1997; 156: 951-958.

100 Lindqvist A, Karjalainen EM, Laitinen LA, et al. Salmeterol resolves airway obstruction but does not possess anti-eosinophil efficacy in newly diagnosed asthma: a randomized, double-blind, parallel group biopsy study comparing the effects of salmeterol, fluticasone propionate, and disodium cromoglycate. J Allergy Clin Immunol 2003; 112: 23-28.

101 Sont JK, Willems LNA, Bel EH, et al. Clinical control and histopathologic outcome of asthma when using airway hyperresponsiveness as an additional guide to long-term treatment. The AMPUL Study Group. Am J Respir Crit Care Med 1999; 159: 1043-1051.

102 Ward C, Pais M, Bish R, et al. Airway inflammation, basement membrane thickening and bronchial hyperresponsiveness in asthma. Thorax 2002; 57: 309-316.

103 Ward C, Reid DW, Orsida BE, et al. Inter-relationships between airway inflammation, reticular basement membrane thickening and bronchial hyper-reactivity to methacholine in asthma; a systematic bronchoalveolar lavage and airway biopsy analysis. Clin Exp Allergy 2005; 35: 1565-1571.

104 Chakir J, Shannon J, Molet S, et al. Airway remodelingassociated mediators in moderate to severe asthma: effect of steroids on TGF- $\beta$, IL-11, IL-17, and type I and type III collagen expression. J Allergy Clin Immunol 2003; 111: 1293-1298.

105 van Rensen EL, Sont JK, Evertse CE, et al. Bronchial CD8 cell infiltrate and lung function decline in asthma. Am J Respir Crit Care Med 2005; 172: 837-841.

106 Zheng L, Orsida B, Whitford H, et al. Longitudinal comparisons of lymphocytes and subtypes between airway wall and bronchoalveolar lavage after human lung transplantation. Transplantation 2005; 80: 185-192.

107 Orsida BE, Li X, Hickey B, Thien F, Wilson JW, Walters EH. Vascularity in asthmatic airways: relation to inhaled steroid dose. Thorax 1999; 54: 289-295.

108 Chetta A, Zanini A, Foresi A, et al. Vascular component of airway remodeling in asthma is reduced by high dose of fluticasone. Am J Respir Crit Care Med 2003; 167: 751-757.

109 Hoshino M, Takahashi M, Takai Y, Sim J, Aoike N. Inhaled corticosteroids decrease vascularity of the bronchial mucosa in patients with asthma. Clin Exp Allergy 2001; 31: 722-730.

110 Goncharova EA, Billington CK, Irani C, et al. Cyclic AMPmobilizing agents and glucocorticoids modulate human smooth muscle cell migration. Am J Respir Cell Mol Biol 2003; 29: 19-27.
111 Altraja A, Laitinen A, Meriste S, et al. Regular albuterol or nedocromil sodium-effects on airway subepithelial tenascin in asthma. Respir Med 1999; 93: 445-453.

112 Walker S, Monteil M, Phelan K, Lasserson TJ, Walters EH. Anti-IgE for chronic asthma in adults and children. Cochrane Database Syst Rev 2006; CD003559.

113 Jonkers RE, van der Zee JS. Anti-IgE and other new immunomodulation-based therapies for allergic asthma. Neth J Med 2005; 63: 121-128.

114 Haselden BM, Larche M, Meng Q, et al. Late asthmatic reactions provoked by intradermal injections of $\mathrm{T}$-cell peptide epitopes are not associated with bronchial mucosal infiltration of eosinophils or $\mathrm{T}(\mathrm{H}) 2$-type cells or with elevated concentrations of histamine or eicosanoids in bronchoalveolar fluid. J Allergy Clin Immunol 2001; 108: 394-401.

115 Flood-Page P, Menzies-Gow A, Phipps S, et al. Anti-IL-5 treatment reduces deposition of ECM proteins in the bronchial subepithelial basement membrane of mild atopic asthmatics. J Clin Invest 2003; 112: 1029-1036.

116 Flood-Page PT, Menzies-Gow AN, Kay AB, Robinson DS. Eosinophil's role remains uncertain as anti-interleukin-5 only partially depletes numbers in asthmatic airway. Am J Respir Crit Care Med 2003; 167: 199-204.

117 Rouhani FN, Meitin CA, Kaler M, Miskins-Hilligloss D, Stylianou M, Levine SJ. Effect of tumour necrosis factor antagonism on allergen-mediated asthmatic airway inflammation. Respir Med 2005; 99: 1175-1182.

118 Rudmann DG, Moore MW, Tepper JS, et al. Modulation of allergic inflammation in mice deficient in TNF receptors. Am J Physiol Lung Cell Mol Physiol 2000; 279: L1047-L1057.

119 Howarth PH, Babu KS, Arshad HS, et al. Tumour necrosis factor $(\mathrm{TNF} \alpha)$ as a novel therapeutic target in symptomatic corticosteroid dependent asthma. Thorax 2005; 60: 1012-1018.

120 Popescu FD. New asthma drugs acting on gene expression. J Cell Mol Med 2003; 7: 475-486.

121 Whitford $\mathrm{H}$, Walters EH, Levvey B, et al. Addition of inhaled corticosteroids to systemic immunosuppression after lung transplantation: a double-blind, placebo-controlled trial. Transplantation 2002; 73: 1793-1799.

122 Yates B, Murphy DM, Forrest IA, et al. Azithromycin reverses airflow obstruction in established bronchiolitis obliterans syndrome. Am J Respir Crit Care Med 2005; 172: 772-775.

123 Verleden GM, Dupont LJ. Azithromycin therapy for patients with bronchiolitis obliterans syndrome after lung transplantation. Transplantation 2004; 77: 1465-1467.

124 Gerhardt SG, McDyer JF, Girgis RE, Conte JV, Yang SC, Orens JB. Maintenance azithromycin therapy for bronchiolitis obliterans syndrome: results of a pilot study. Am J Respir Crit Care Med 2003; 168: 121-125. 